ISSN 2073-4441

www.mdpi.com/journal/water

\title{
Article
}

\section{Fungal Biosorption, An Innovative Treatment for the Decolourisation and Detoxification of Textile Effluents}

\author{
Valeria Tigini ${ }^{1}$, Valeria Prigione ${ }^{1}$, Pietro Giansanti ${ }^{2}$, Antonella Mangiavillano ${ }^{2}$, \\ Antonella Pannocchia ${ }^{2}$ and Giovanna Cristina Varese ${ }^{1, *}$
}

1 Department of Plant Biology, University of Torino, viale Mattioli 25, 10125 Torino, Italy;

E-Mails: valeria.tigini@unito.it (V.T.) ; valeria.prigione@unito.it (V.P.)

2 Laboratorio Analisi del Dipartimento Provinciale della Provincia di Torino (SC06), Sede di Torino, via Pio VII, 9-10135 Torino, Italy; E-Mails: p.giansanti@arpa.piemonte.it (P.G.); antonella.mangiavillano@arpa.piemonte.it (A.M.); a.pannocchia@arpa.piemonte.it (A.P.)

* Author to whom correspondence should be addressed; E-Mail: cristina.varese @ unito.it; Tel.: +39-011-670-5984; Fax: +39-011-670-5962.

Received: 15 July 2010; in revised form: 19 August 2010 / Accepted: 24 August 2010 /

Published: 31 August 2010

\begin{abstract}
Textile effluents are among the most difficult-to-treat wastewaters, due to their considerable amount of recalcitrant and toxic substances. Fungal biosorption is viewed as a valuable additional treatment for removing pollutants from textile wastewaters. In this study the efficiency of Cunninghamella elegans biomass in terms of contaminants, COD and toxicity reduction was tested against textile effluents sampled in different points of wastewater treatment plants. The results showed that $C$. elegans is a promising candidate for the decolourisation and detoxification of textile wastewaters and its versatility makes it very competitive compared with conventional sorbents adopted in industrial processes.
\end{abstract}

Keywords: textile wastewaters; biosorption treatment; fungi; dyes; salts; surfactants; toxicity

\section{Introduction}

Industrial effluents contribute enormously to water deterioration and their treatment is the subject of discussion and regulation in many countries. Textile effluents are among the most difficult-to-treat wastewaters due to their considerable amount of toxic substances [1]. 
Colour is the first signs of contamination recognized in a wastewater, since even a very small quantity of dyes is highly visible in it. Because of their high resistance to degradation, dyes tend to be unaffected by conventional treatment systems [2]. Some of them have also a tendency to bio-accumulate $[3,4]$. The dyestuffs discharge into water bodies reduces water transparency and thus the dissolved oxygen concentration, affecting aerobic organisms [5]. The presence of dyes or their degradation products in water, even at very low concentrations, can also cause human health disorders [6].

Besides dyes, concern recently raised over other organic and inorganic pollutants, which characterised textile wastewaters. Surfactants, for instance, are organic compounds largely used in these industrial sectors for both the preparation of row materials and the finishing process. They contain non-polar alkyl chains and a polar group, from which the classification in anionic, cationic, non-ionic and amphoteric or zwitterionic surfactants depends. Because of their reduced water solubility with respect to the parental molecules, these compounds can accumulate in water sediments and in the fat tissues of aquatic animals [7]. New synthetic surfactants generally consist in linear chains, while the oldest ones possesses most recalcitrant branched chains or aromatic rings; nevertheless, the environmental impact of new synthetic surfactants is still very high because of their low biodegradability, mainly due to the non-polar component of the molecule.

Among inorganic pollutants, salts are consumed in the largest amount in the dye process. Their concentration can reach values around $70-90 \mathrm{~g} \mathrm{~L}^{-1}$ and, since salts are not fixed to tissue, about the $75 \%$ of them end up in the wastewaters [8]. In most cases, the traditional methods of water treatment are unable to eliminate salts [9]: actually, according to the EIPPCB (European Integrated Pollution Prevention and Control Bureau) estimates, the textile industry releases more than 0.2 million of tons of salts in the environment every year [10]. Consequently, textile wastewaters can lead to an alteration of the aquatic ecosystems equilibrium. Moreover, salts in surface waters can affect also the agricultural activity and salinization of underground fresh water can seriously compromise the drinking water resources [11].

An important and often underestimated aspect is the effluent toxicity and its evolution during the wastewater treatment, as required by the Integrated Pollution Prevention and Control (IPPC) regulations introduced in the European Union (Council Directive 96/61/EC). In same cases, in fact, the decolourisation process results in the formation of colourless but toxic and mutagenic compounds, which increase the wastewater toxicity. Chemical procedures alone cannot provide sufficient information on the potential harmful effects of pollutants on the aquatic environment and are unable to predict the effects on the organisms in the ecosystem. Moreover, the wastewaters toxicity and its impact on the receiving water environment cannot be reliably predicted from the known toxicity of the individual constituents; indeed, the result of the simultaneous presence of more chemical species in wastewaters can be different from the simple sum of their single toxic effects, turning in a synergistic combined effect. Ecotoxicity assays can detect the total impact of the pollutants only testing the complete industrial wastewater samples as specified in EC Directive 2008/1 IPPC.

These considerations show that efficient, eco-friendly and cost effective remedies for wastewater treatment are needed. Among biotechnological techniques, biosorption can be seen as one of the most valuable choice for the removal of pollutants from wastewaters. Biosorption is a physico-chemical process, defined as the removal of substances from solution by biological material. The main virtutes 
of biosorption are the high efficiency, cost effectiveness and good capacity of removing pollutants from large volumes [12]. In particular, fungal biomass proved to be particularly suitable among the types of biosorbent, thanks to chemical and physical characteristics of their cell wall, which might be exploited in the binding of different pollutants. In addition, they easily grow and produce high yields of biomass on different sources with low nutritional requirements, and biomass separation from the growth liquid medium constitutes a simple operation [13].

Most of the studies on biosorption concentrate on dye removal from single dye solutions, however recent literature indicates the need to generate performance data on real or simulated industrial effluents, since many biotic and abiotic factors can affect biosorption process [12].

In previous studies, the biomass of the fungus Cunninghamella elegans (MUT 2861) was effective in removing a wide spectrum of dyes, irrespective of their concentrations and of the physical-chemical characteristics of the wastewaters towards simulated effluents [14].

In the first part of this study the efficiency of $C$. elegans biomass in terms of reduction of both contaminants and COD was screened against real industrial textile effluents coming from different sampling points of wastewater treatment plants. In the second part, the effect of biomass-wastewater ratio on contaminants removal and toxicity reduction was investigated by using four different amounts of fungal biomass.

\section{Materials and Methods}

\subsection{Industrial Textile Wastewaters}

The 9 real wastewaters tested in this study were kindly provided by textile industries based in Region Lombardy (Italy), which mainly process cotton and synthetic fibres. They were sampled in different points of 4 wastewater treatment plants (WWTPs): in homogenization tank, after the biological treatment with activated sludge and after tertiary treatments before the discharge in superficial fresh water (Table 1).

The plant A treats about $4,500 \mathrm{~m}^{3} \mathrm{~d}^{-1}$ of wastewaters coming from cotton, polyester and polyamide dyeing processes, and collects also wastewaters coming from other industrial sectors. It has four treatment stages and the last two (A3 and A4) are set in parallel, before the wastewater discharge.

The plant $B$ is a small plant (about $300 \mathrm{~m}^{3} \mathrm{~d}^{-1}$ ) treating wastewaters coming exclusively from polyester and polyamide dyeing processes with acid and disperse dyes.

The plant $\mathrm{C}$ treats about $3,000-4,000 \mathrm{~m}^{3} \mathrm{~d}^{-1}$ of wastewaters coming from cotton dyeing process with reactive and vat dyes.

The plant D treats about $13,000 \mathrm{~m}^{3} \mathrm{~d}^{-1}$ of wastewaters coming from cotton dyeing with reactive dyes in continuous process. 
Table 1. Characterisation of real effluents sampled in different point of WWTPs: acronyms, $\mathrm{pH}$ values, $\mathrm{Cl}^{-}\left(\mathrm{mg} \mathrm{L}^{-1}\right), \mathrm{SO}_{4}{ }^{2-}\left(\mathrm{mg} \mathrm{L}^{-1}\right), \mathrm{COD}\left(\mathrm{mg} \mathrm{L}^{-1}\right)$, anionic surfactants (AN) $\left(\mathrm{mg} \mathrm{L}^{-1}\right)$, non-ionic surfactants (NS) $\left(\mathrm{mg} \mathrm{L}^{-1}\right)$ and the value of the integral of the absorbance spectrum (Abs).

\begin{tabular}{|l|c|c|c|c|c|c|c|c|}
\hline Effluent & Acronym & $\mathbf{p H}$ & $\mathbf{C l}^{-}$ & $\mathbf{S O}_{\mathbf{4}}{ }^{-}$ & $\mathbf{C O D}$ & $\mathbf{A S}$ & $\mathbf{N S}$ & Abs \\
\hline Plant A-homogenization tank & A1 & 8.4 & 913 & 176 & 543 & 1.9 & 5.7 & 180 \\
\hline Plant A-after activated sludge & A2 & 7.4 & 780 & 200 & 313 & 0.7 & 0.8 & 170 \\
\hline Plant A-after polyelectrolyte & A3 & 7.2 & 850 & 210 & 120 & 0.4 & 0.8 & 25 \\
\hline Plant A-after ozonation & A4 & 7.3 & 790 & 209 & - & - & - & 15 \\
\hline Plant B-homogenization tank & B1 & 7.1 & - & - & - & - & - & 121 \\
\hline Plant C-homogenization tank & C1 & 8.8 & - & - & - & - & - & 87 \\
\hline Plant C-after activated sludge & C2 & 7.7 & - & - & - & - & - & 13 \\
\hline Plant D-homogenization tank & D1 & 7.7 & - & - & - & - & - & 15 \\
\hline Plant D-after activated sludge & D2 & 7.9 & - & - & - & - & - & 13 \\
\hline Plant D-after activated carbons & D3 & 6.2 & - & - & - & - & - & 5 \\
\hline
\end{tabular}

\subsection{Biosorption Experiments for the Screening of the Biomass Effectiveness}

The organism used for biosorption experiment, Cunninghamella elegans Lendner (MUT 2861), was obtained from the Mycotheca Universitatis Taurinensis Collection (MUT, University of Turin, Department of Plant Biology). The fungus was cultured on starch as carbon source $\left(18 \mathrm{~g} \mathrm{~L}^{-1}\right.$ starch from cereals, $2 \mathrm{~g} \mathrm{~L}^{-1}$ ammonium tartrate, $2 \mathrm{~g} \mathrm{~L}^{-1} \mathrm{KH}_{2} \mathrm{PO}_{4}, 0.5 \mathrm{~g} \mathrm{~L}^{-1}, \mathrm{MgSO}_{4} \cdot 7 \mathrm{H}_{2} \mathrm{O}, 0.1 \mathrm{~g} 11 \mathrm{CaCl}_{2}$ $2 \mathrm{H}_{2} \mathrm{O}, 10 \mathrm{~mL}$ mineral stock solution). Then the biomass was heat-inactivated, lyophilised (Lyophiliser LIO 10P, Cinquepascal, Trezzano s/n, Italy) and powdered.

The biomass was weighted and $2.6 \mathrm{~g}$ dry weight of it were placed in $500 \mathrm{~mL}$ Erlenmayer flasks containing $250 \mathrm{~mL}$ of effluents and incubated at $30{ }^{\circ} \mathrm{C}$ and $150 \mathrm{rpm}$ in a Minitron Infors orbital shaker (Bottmingen, $\mathrm{CH}$ ). Wastewaters without biomass were used as abiotic controls. Each trial was performed three times. After $2 \mathrm{~h}$, the biomass was filtered with a paper filter (Whatman type 1) and the decolourisation percentage (DP) was calculated as the extent of decrease of the adsorbance spectrum area from $360 \mathrm{~nm}$ to $790 \mathrm{~nm}$, with respect to that of the abiotic control.

The significance of differences $(p \leq 0.05)$ among the DP values was calculated using the Mann-Whitney test (SYSTAT 10 for windows SPSS inc., 2000).

Chemical analyses were performed towards samples coming from one of the four plants. Composite samples were originated from a mix of three repetitions of each trial and subsequently analysed. $\mathrm{Cl}^{-}$ and $\mathrm{SO}_{4}{ }^{2-}$ ions measurements were performed, according to the method APAT CNR IRSA 4020-2003, towards samples of a plant selected among the four.

The determination of COD was performed with the dichromate method (APAT CNR IRSA 5130-2003) using the HACH (COD High range vials) apparatus according to the manufacturer's instructions. A calibration curve was obtained using the HACH COD standard solution (800 $\mathrm{mg} \mathrm{O}_{2} \mathrm{~L}^{-1}$ ).

Non-ionic surfactants measurements were performed following the methodology Unichim 980/1-1993. Anionic surfactants measurements were performed following the methodology APAT CNR IRSA 5170-2003. 


\subsection{Effect of Biomass-Wastewater Ratio}

In order to optimize the biosorption treatment, the effect of different amounts of fungal biomass was evaluated. Four biomass-wastewater ratio were used: $10.0 \mathrm{~g} \mathrm{~L}^{-1}, 5.0 \mathrm{~g} \mathrm{~L}^{-1}, 1.0 \mathrm{~g} \mathrm{~L}^{-1}$, and $0.5 \mathrm{~g} \mathrm{~L}^{-1}$. Effluents from the plant A, selected as a case study for this experiment, were sampled before (A2) and after the decolourisation with polyelectrolyte (A3) or ozonation (A4), the last two being parallel tertiary treatments.

Wastewaters were treated with $C$. elegans biomass obtained as already described, while samples without biomass were used as abiotic controls. Each trial was performed three times. The wastewaters were incubated at $30{ }^{\circ} \mathrm{C}$ and $150 \mathrm{rpm}$ and after 30', $1 \mathrm{~h}$ and $2 \mathrm{~h}, 200 \mu \mathrm{L}$ were sampled and spectrophotometrically analysed in order to calculate the decolourisation percentage (DP) as described above.

At the end of the experiment, the biomass was filtered on filter paper (Whatman type 1) and composite samples were originated from the mix of the three repetitions of each trial. $\mathrm{Cl}^{-}$and $\mathrm{SO}_{4}{ }^{2-}$ ions were measured following the methodology APAT CNR IRSA 4020-2003.

\subsection{Ecotoxicity Assay of Wastewaters}

The untreated wastewaters were thoroughly characterised from the ecotoxicological point of view by means of a battery of ecotoxicity tests with organisms belonging to different trophic level. This operation was performed before the fungal treatment.

The test of the bacteria luminescence inhibition (UNI EN ISO 11348-3) was performed using the Microtox ${ }^{\circledR}$ toxicity system (Microtox Model 500; Microbics Corp., USA), which automatically registration the luminescence. Freeze-dried marine luminescent bacteria (Vibrio fischeri strain NRRL B-11177) were bought from Ramcon A/S (Birkeroed, Denmark). Each dose-response curve consisted of eight dilutions, each in duplicate and with four controls. The luminescence intensity in all cuvettes was measured before the addition of the wastewaters and after 5, 15 and 30 minutes. Automatic colour correction was performed when necessary. The inhibitory effect was calculated using the computer program for Microtox Acute Toxicity Test, Azur Environmental Ltd., UK.

The test of the algae growth inhibition (UNI EN ISO 8692:2005) was performed for both the acute and chronic toxicity using the unicellular alga Pseudokirchneriella subcapitata (Korshikov) Hindak originating from the Agenzia Regionale per la Protezione dell'Ambiente (ARPA Piemonte, Grugliasco, TO). Each dose-response curve consisted of 12 dilutions (in triplicate). A repetition without the algal inoculum was used as abiotic negative control. The biotic negative control (algal inoculum in algal medium) was performed with six repetitions. After $48 \mathrm{~h}$ of incubation, the cells concentration was measured with a Coulter Counter (Beckman Coulter Z2) calibrated for 3-5 $\mu \mathrm{m}$ size cells. The chronic toxicity data were processed using both parametric (Shapiro-Wilk's and Bartlet tests) and non parametric (Bonferroni $t$ test) statistical tests by means of the software TOXCALC, executed in compliance with the US-EPA protocol.

The test of the root growth inhibition (UNICHIM N. 1651: 2003) was performed using seeds of two dicotyledonous plants, Cucumis sativus L. and Lepidium sativum L., purchased from Ingegnoli S.p.A. (Milano). Each dose-response curve consisted of eight dilutions, each in four replicates. For each 
species, ten seeds were placed in $9 \mathrm{~cm}$ Petri dishes, containing $5 \mathrm{~mL}$ of sample and a paper filter (Whatman No.1). The control was performed in four replicates, using distilled water. The seeds were incubated for $72 \mathrm{~h}$ in a dark environment at $25{ }^{\circ} \mathrm{C}$. At the end of the test, the germinated seeds were counted and their radical extension was measured using standard procedures.

The test with the crustaceous Daphnia magna Straus (UNI EN ISO 6341:99) was performed using a strain cultured at ARPA Piemonte, as specified by the standard method. The considered endpoint was the crustaceans' immobilisation. Each dose-response curve consisted of at least six dilutions, each in four replicates of five animals. The test volume was $5 \mathrm{~mL}$ and 6 -well plates were used. Control was performed with six repetitions. Immobile animals were counted after $24 \mathrm{~h}$ and the response given as percent mobile animals with respect to the negative control.

The mutagenicity Ames test (ISO 16240/2005) was performed with both TA98 and TA100 strains of the bacterium Salmonella typhimurium to detect frameshift and base-pair substitution mutations, respectively. The strains were obtained from IMTECH (Chandigarh). In order to observe whether the parent molecule's metabolites formed in the hepatic system were positive, the test was performed using pre-incubation procedure with and without the $\mathrm{S} 9$ mix metabolic activation. For each plate, $0.5 \mathrm{~mL}$ of $10 \% \mathrm{~S} 9 \mathrm{mix}$ and $0.1 \mathrm{~mL}$ of sample were used. After $48 \mathrm{~h}$ incubation of agar plates at $37{ }^{\circ} \mathrm{C}$, the counting of bacterial colonies was performed.

The toxicity reduction after biosorption treatment was assesses by means of the test organism, which resulted the most sensitive one among the battery performed before the biosorption treatment.

\section{Results}

\subsection{Screening of Decolourisation Yields}

After a $2 \mathrm{~h}$ treatment, the DPs of effluents sampled from WWTPs ranged between $89 \%$ and $8 \%$.

In detail, for the plant A, very high DPs (>85\%) were recorded towards the samples from the homogenization tank and after the activated sludge; on the contrary, a good colour reduction was obtained even after the tertiary treatments (56\%) (Figure 1).

The fungal treatment reduced by about $75 \%$ the colour of the homogenization tank of the plant B, which was characterized by a low concentration of dyes in relation to the type of synthetic fibres treated. In the plant $\mathrm{C}$, the fungal treatment reduced by about $48 \%$ the colour of the homogenization tank and by about $55 \%$ the colour of the wastewater after the activated sludge. In the plant $\mathrm{D}$, the biosorption treatment reduced by about $34 \%$ the colour of the homogenization tank and of approximately $29 \%$ the colour of the wastewater after the activated sludge. Noteworthy, the fungal biomass was able to reduce the colour of about $8 \%$ even after the tertiary decolourization treatments with activated carbons and polyelectrolyte (Figure 1). 
Figure 1. Decolourisation percentages of effluents sampled in different points of the wastewater treatment plants with $2.6 \mathrm{~g}$ of lyophilised biomass of $C$. elegans. a, b, c..., g indicate significant difference $(\mathrm{p} \leq 0.05$, Mann-Whitney test $)$ among the decolourisation percentages.

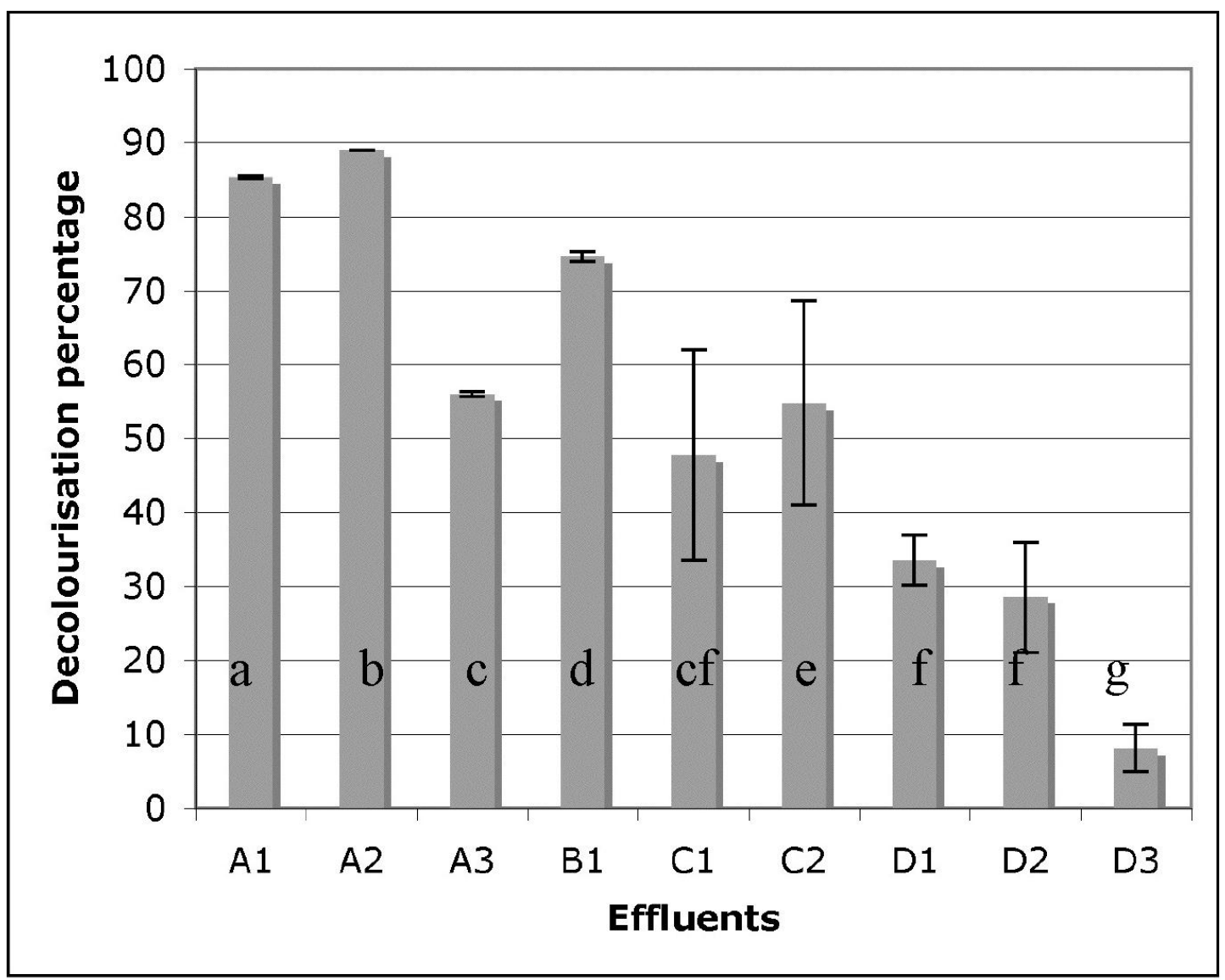

\subsection{Removal of Other Pollutants}

The samples of the plant A were selected for the chemical analysis focused on the assessment of the removal of salts, surfactants and COD. These results are shown in Figure 2.

$\mathrm{Cl}^{-}$always increased after biosorption treatment from $13 \%$ (A1 and A2) to 21\% (A3), while $\mathrm{SO}_{4}{ }^{2-}$ always decreased from $8 \%$ (A1) to $12 \%$ (A2). COD decreased only in the case of A1 (12\%). Anionic surfactants decreased in A1 (16\%) and especially in A2 (43\%), while non-ionic surfactants decreased only in A1 (63\%). 
Figure 2. Removal percentages of chloride, COD, sulphate, anionic and non-ionic surfactants and colour after $2 \mathrm{~h}$ biosorption treatment with $2.6 \mathrm{~g}$ of lyophilised biomass of C. elegans. (A1) homogenization tank; (A2) after activated sludge; (A3) after decolourisation treatment.
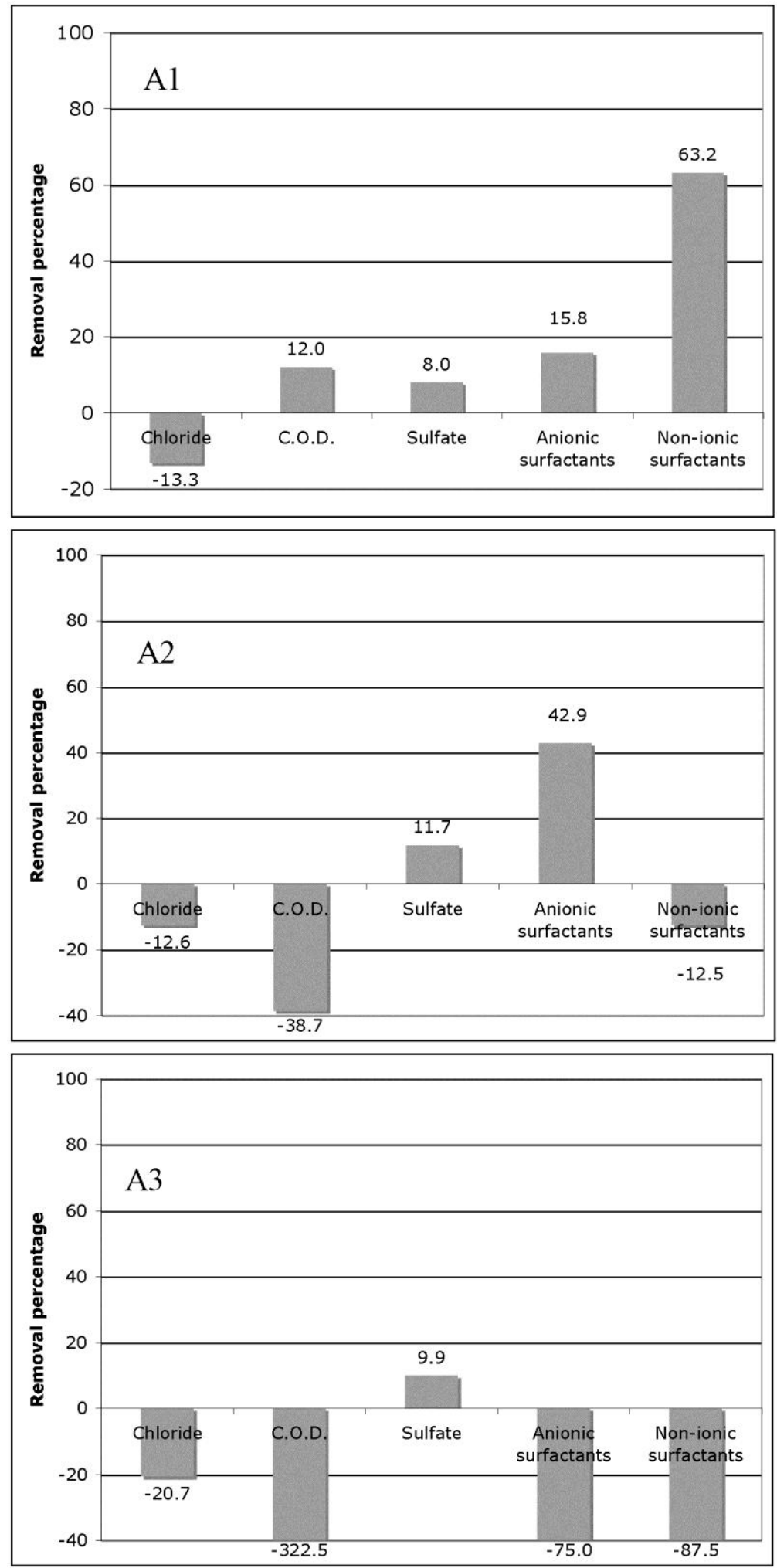


\subsection{Effect of the Biomass-Wastewater Ratio}

The biosorption treatment with fungal biomass resulted in a clear reduction of the absorbance spectrum of points A2 and A3 in the whole range of monitored lambda. On the contrary, in A4, despite the decrease of the absorbance spectrum among 360 and $400 \mathrm{~nm}$, an increase of the spectrum between 600 and $790 \mathrm{~nm}$ was recorded. These modifications in absorbance spectrum resulted in an unchanged spectrum area and, thus, in a null decolourisation percentage.

The decolourisation percentages of A2 and A3 after biosorption treatment with C. elegans biomass are shown in Figure 3.

Figure 3. Decolourisation percentage (mean \pm standard deviation of three repetitions) of A 2 and A3 after $30 \mathrm{~min}, 1 \mathrm{~h}$ and $2 \mathrm{~h}$ of treatment with the biomass of C. elegans obtained with different biomass-wastewater ratio. $a, b, c, d$ indicate significant differences $(p \leq 0.05$, Mann-Whitney test) among decolourisation percentages achieved by different amounts of biomass within the same time; $x, y$ indicate significant differences $(p \leq 0.05$, Mann-Whitney test) among decolourisation percentages achieved within different time by the same amount of biomass.
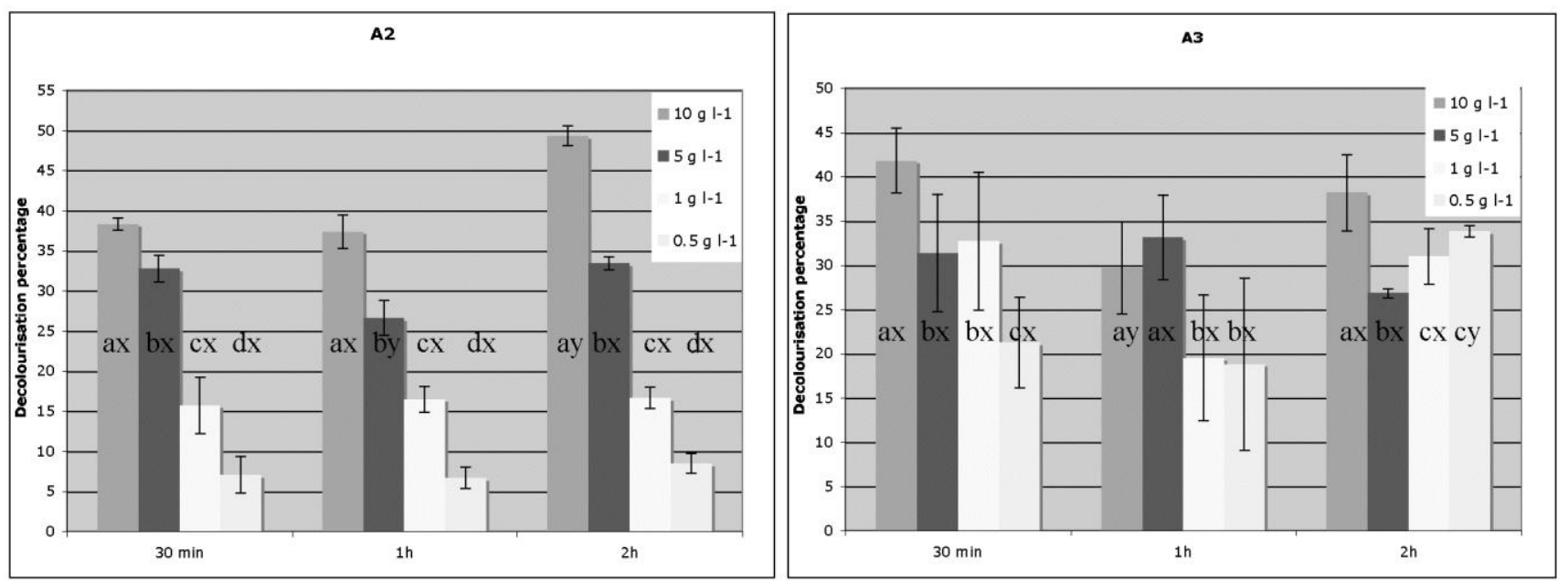

Treatment with $10 \mathrm{~g} \mathrm{~L}^{-1}$ of biomass resulted in a substantial decolourisation of both A2 and A3 ( $49 \%$ and $41 \%$ of decolourisation percentage, respectively). Appreciable rates of decolourisation were obtained with $5 \mathrm{~g} \mathrm{~L}^{-1}$ of biomass and, in the case of the wastewater A3, even with $1 \mathrm{~g} \mathrm{~L}^{-1}$ and $0.5 \mathrm{~g} \mathrm{~L}^{-1}$ biomass. In all cases, the biosorption process acted very fast; actually, most of the final decolourisation was obtained after 30 min of incubation. Only in two cases (A2 treated with $10 \mathrm{~g} \mathrm{~L}^{-1}$ of biomass and $\mathrm{A} 3$ treated with $0.5 \mathrm{~g} \mathrm{~L}^{-1}$ biomass), to get a significant improvement in the decolourisation percentage between $30 \mathrm{~min}$ and $2 \mathrm{~h}$ of treatment were required.

In addition to decolourisation, the reduction of $\mathrm{COD}$ and salts $\left(\mathrm{Cl}^{-}\right.$and $\left.\mathrm{SO}_{4}{ }^{2-}\right)$ was analyzed. Only in three cases a reduction in $\mathrm{COD}$ ( $\mathrm{A} 3$ and $\mathrm{A} 4$ treated with $1 \mathrm{~g} \mathrm{~L}^{-1}$ biomass and $\mathrm{A} 3$ treated with $0.5 \mathrm{~g} \mathrm{~L}^{-1}$ of biomass) was recorded. The variation of COD was almost always proportional to the amount of used biomass. Despite the general increase in COD, all samples treated with $1 \mathrm{~g} \mathrm{~L}^{-1}$ and $0.5 \mathrm{~g} \mathrm{~L}^{-1}$ of fungal biomass were complying with the normative for the discharge in surface water (Table 2). 
Table 2. COD amount $\left(\mathrm{mg} \mathrm{L}^{-1}\right)$ in treated A2, A3 and A4 and variation percentage with respect to the untreated samples.

\begin{tabular}{|c|c|c|c|c|c|c|c|c|}
\hline & \multicolumn{2}{|c|}{ Biomass 10 $\mathbf{g ~ L}^{-\mathbf{1}}$} & \multicolumn{2}{c|}{ Biomass 5 $\mathbf{g ~ L}^{-\mathbf{1}}$} & \multicolumn{2}{c|}{ Biomass 1 $\mathbf{g ~ L}^{-\mathbf{1}}$} & \multicolumn{2}{c|}{ Biomass 0.5 g L $^{\mathbf{- 1}}$} \\
\cline { 2 - 9 } & $\mathbf{m g ~ L}^{-1}$ & Variation & $\mathbf{m g ~ L}^{-\mathbf{1}}$ & Variation & $\mathbf{m g ~ L}^{-\mathbf{1}}$ & Variation & mg L $^{-1}$ & Variation \\
\hline $\mathbf{A 2}$ & 440 & $+203.4 \%$ & 210 & $+10.3 \%$ & 160 & $+10.3 \%$ & 160 & $+203.4 \%$ \\
\hline $\mathbf{A 3}$ & 420 & $+189.7 \%$ & 200 & $+37.9 \%$ & 140 & $-3.4 \%$ & 420 & $+189.7 \%$ \\
\hline $\mathbf{A 4}$ & 440 & $+203.4 \%$ & 290 & $+100.0 \%$ & 130 & $-10.3 \% \%$ & 120 & $-17.2 \%$ \\
\hline
\end{tabular}

In all cases, biosorption treatment resulted in the reduction of $\mathrm{Cl}^{-}$, with removal percentages ranging between $9 \%$ and $45 \%$ (Figure 4). For $\mathrm{A} 2$ and $\mathrm{A} 3$ the $\mathrm{Cl}^{-}$reduction was proportional to the amount of biomass, while for A4 the trend was opposite, with the exception of the treatment with $10 \mathrm{~g} \mathrm{~L}^{-1}$ biomass. The biosorption treatment almost always decreased the $\mathrm{SO}_{4}{ }^{2-}$ in solution, with removal percentages ranging between $5 \%$ and $40 \%$. In this case, a clear correlation between removal percentage and biomass amount was not recorded (Figure 4).

Figure 4. Removal percentages of $\mathrm{Cl}^{-}$and $\mathrm{SO}_{4}{ }^{2-}$ ions of $\mathrm{A} 2$ and $\mathrm{A} 3$ obtained after 30 minutes treatment with different biomass-wastewater ratio.
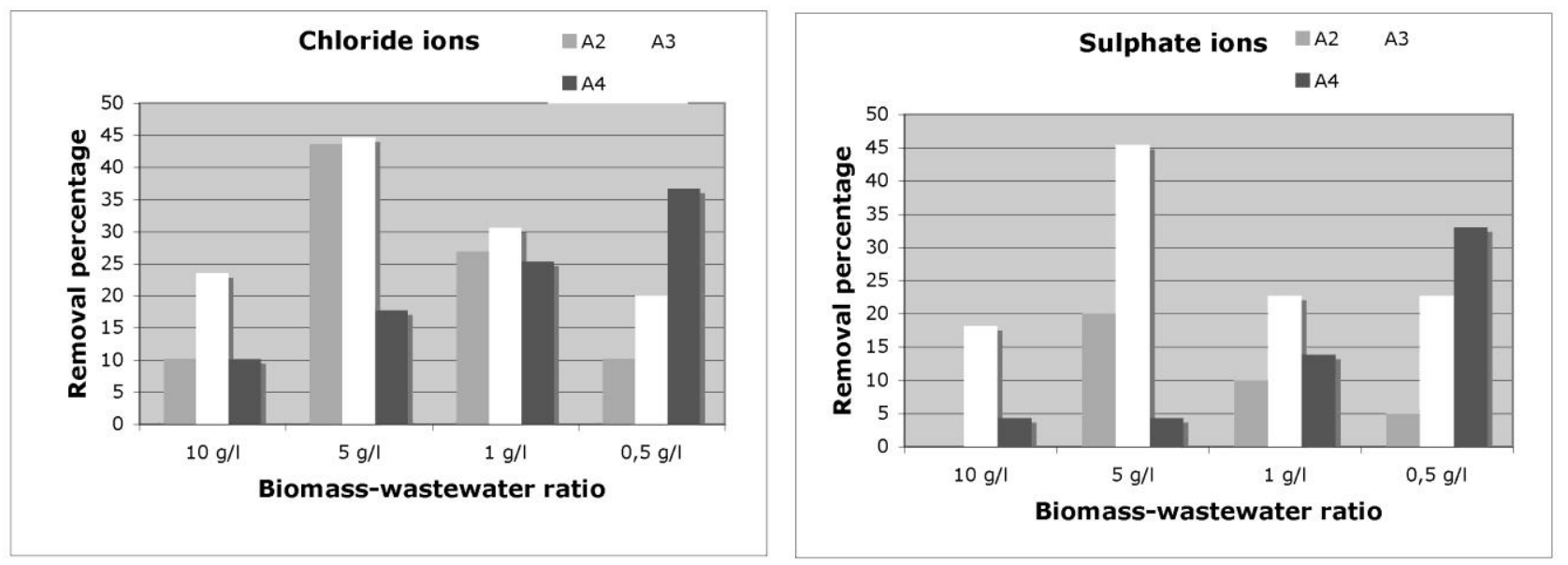

\subsection{Ecotoxicity of Wastewaters before and after the Biosorption Treatment}

The results of the acute ecotoxicity assays are summarized in Table 3.

The acute toxicity test with bioluminescent bacteria $\left(\right.$ Microtox $^{\circledR}$ ) revealed a moderate toxicity (up to $14 \%$ at the net of the colour interference) against the A2 sample. The exposure time slightly affected the extent of toxicity, since a slight increase in toxicity with increasing minutes of exposure was found. Decolourisation treatment by means of polyelectrolyte (A3) consistently reduced the wastewater toxicity towards bacteria, although a correlation between time of exposure and toxicity was persisting. The treatment with ozone (A4) almost doubled the wastewater toxicity towards bioluminescent bacteria. This increment was observed for all exposure times. In addition, the toxicity was proportional to the exposure time ranging from $24 \%$ ( $5 \mathrm{~min}$ ) to $44 \%$ (30 $\mathrm{min}$ ).

The alga $P$. subcapitata showed an increase of the wastewaters toxicity passing through A2 (19\%), A4 (34\%) and A3 (44\%). 
The growth of L. sativum roots was biostimulated (up to 15\%) in A2 and A4, whereas a slight inhibition (5\%) was found in A3.

On the contrary, $C$. sativus resulted the most sensitive organism towards all wastewaters: in A2 the $63 \%$ inhibition of its root growth was observed; the decolouration treatment with polyelectrolyte did not change significantly the toxicity of the wastewater (63\% inhibition), whereas the ozonation slightly lowered the toxicity (59\% inhibition).

Finally, D. magna was not sensitive to any sample tested.

Table 3. Acute toxicity of A2, A3 and A4 towards different organisms.

\begin{tabular}{|c|c|c|c|c|}
\hline & & A2 (after activated sludge) & $\begin{array}{c}\text { A3 (after } \\
\text { polyelectrolyte) }\end{array}$ & A4 (after ozonation) \\
\hline \multirow{3}{*}{ 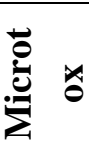 } & $5 \mathrm{~min}$ & $12.1 \%$ & $9.5 \%$ & $23.6 \%$ \\
\hline & $15 \mathrm{~min}$ & $12.7 \%$ & $10.2 \%$ & $36.2 \%$ \\
\hline & $30 \mathrm{~min}$ & $14.4 \%$ & $11.4 \%$ & $43.7 \%$ \\
\hline \multicolumn{2}{|c|}{ P. subcapitata } & $19.0 \%$ & $43.8 \%$ & $34.3 \%$ \\
\hline \multicolumn{2}{|c|}{ L. sativum } & $-14.2 \%$ & $5.4 \%$ & $-15.3 \%$ \\
\hline \multicolumn{2}{|c|}{ C. sativus } & $63.0 \%$ & $62.9 \%$ & $59.3 \%$ \\
\hline \multicolumn{2}{|c|}{ D. magna } & $0.0 \%$ & $0.0 \%$ & $0.0 \%$ \\
\hline
\end{tabular}

In addition to these acute toxicity tests, a chronic toxicity test with $P$. subcapitata was set up, allowing to observe the toxic effect caused by a longer exposure times. This essay identified for each sample the maximum dose for which no toxic effects were observed (No Observed Effect Concentration, NOEC) and the lowest dose at which toxic effects could be observed (Lowest Observed Effect Concentration, LOEC). The chronic toxicity of wastewaters was reduced after the decolourisation treatment: actually both NOEC and LOEC increased from A2 to A3 (Table 4). The ozone treatment, on the contrary, did not change the degree of the chronic toxicity with respect to A2.

Table 4. Chronic toxicity of A2, A3 and A4 towards P. subcapitata.

\begin{tabular}{|c|c|c|c|}
\hline & A2 (after activated sludge) & A3 (after polyelectrolyte) & A4 (after ozonation) \\
\hline NOEC & $<5 \%$ & $10 \%$ & $<5 \%$ \\
\hline LOEC & $5 \%$ & $20 \%$ & $5 \%$ \\
\hline
\end{tabular}

All samples showed a null mutagenicity effect against strains TA100 and TA98, both in the presence and absence of the metabolic activator S9.

The acute toxicity test organism selected for testing toxicity after the biosorption treatment was $C$. sativus, it resulted the most sensitive one towards the three wastewaters. The biosorption treatment with the fungal biomass significantly decreased the toxicity of all samples, from 56\% (A3 treated with $5 \mathrm{~g} \mathrm{~L}^{-1}$ ) to $100 \%$ (A4), actually the inhibition of the root growth of $C$. sativus was always lower than $27 \%$. In the case of $A 4$, a biostimulation effect was recorded (up to $16 \%$ ). The detoxification did not result proportional to decolourisation rate, nor to the salts reduction, nor to the biomass-wastewater ratio (Table 5). 
Table 5. Measurement of toxicity after biosorption treatment of A2, A3 and A4: inhibition percentage of $C$. sativus root growth and variation percentage compared to untreated samples.

\begin{tabular}{|c|c|c|c|c|c|c|}
\hline \multirow{2}{*}{$\begin{array}{c}\text { Biomass- } \\
\text { wastewater ratio }\end{array}$} & \multicolumn{2}{|c|}{ A2 (after activated sludge) } & \multicolumn{2}{|c|}{ A3 (after polyelectrolite) } & \multicolumn{2}{|c|}{ A4 (after ozonation) } \\
\hline & $\begin{array}{l}\text { Inhibition of } \\
100 \% \text { dose }\end{array}$ & Variation & $\begin{array}{c}\text { Inhibition of } \\
100 \% \text { dose }\end{array}$ & Variation & $\begin{array}{c}\text { Inhibition of } \\
100 \% \text { dose }\end{array}$ & Variation \\
\hline $10 \mathrm{~g} \mathrm{~L}^{-1}$ & $8.0 \%$ & $-87.3 \%$ & $6.3 \%$ & $-90.0 \%$ & $-15.6 \%$ & $100 \%$ \\
\hline $5 \mathrm{~g} \mathrm{~L}^{-1}$ & $11.9 \%$ & $-81.1 \%$ & $26.6 \%$ & $-57.7 \%$ & $-5.8 \%$ & $100 \%$ \\
\hline $1 \mathrm{~g} \mathrm{~L}^{-1}$ & $6.9 \%$ & $-89.0 \%$ & $14.8 \%$ & $-76.5 \%$ & $-7.3 \%$ & $100 \%$ \\
\hline $0.5 \mathrm{~g} \mathrm{~L}^{-1}$ & $10.6 \%$ & $-83.2 \%$ & $8.9 \%$ & $-85.9 \%$ & $-8.6 \%$ & $100 \%$ \\
\hline
\end{tabular}

\section{Discussion}

Effectiveness assessment of biosorption process must be done in conjunction with industrial users/clients and requires specific process engineering expertise and a serious development capital commitment [12]. Actually, textile industry needs a deep innovation in wastewater treatment, since their wastewaters are considered among the most polluted in all the industrial sectors $[15,16]$. Moreover, the costs for wastewater management are very onerous for textile industries. On the other hand, textile industry demands a large quantity of water, which in many countries is becoming a precious and rare commodity that should be reused in textile process.

In this work, $C$. elegans biomass was used in the batch biosorption treatment of real textile wastewaters, representative of different dyeing processes. C. elegans biomass was screened in the treatment of samples coming from different points of several WWTPs, in order to verify the most suitable points for applying the biosorption treatment.

This fungal biomass resulted effective in removing dyes in all heterogeneous conditions in which dyes can be complexed with other pollutants present in the final wastewater. This is very important from an applicative point of view, since most of the innovative biosorbents are quite ineffective in real conditions [4].

In the authors' opinion, the most suitable step for $C$. elegans exploitation is the primary treatment, i.e., the homogenization tank. Actually, the highest decolourisation yields were obtained towards these samples. This could be due both to the higher dye concentration, which characterizes the wastewaters coming from this step of WWTPs, and to the lower interaction with bacteria and protozoa, which increases after the treatment with activated sludge. Moreover, performing biosorption before the activated sludge could enhance the treatability of effluents in the subsequent stages of the WWTPs thanks to the toxicity reduction. As a consequence, this process would reduce the pollution load of the aeration tank that will turn into more effective biological treatment, thus reducing the need for expensive tertiary treatments. Finally, the activated sludge could easily reduced the COD increase that may occur after biosorption treatment, probably due to both organic substances released by the fungal biomass and to bacterial and protozoan activity. 
On the other hand, the decolourisation results obtained after secondary or tertiary treatments indicate that $C$. elegans biomass is an excellent biosorbent, which could be a valid alternative or integration to activated carbons, polyelectrolyte or ozonation.

Noteworthy, $C$. elegans biomass showed an extraordinary versatility in adsorbing different molecules: in addition to dyes, also salts and surfactants often decreased after the biosorption treatment. Moreover, this biomass already showed high affinity towards heavy metals (CrIII) present in a real tannery wastewater [17]. The aspecificity characterizing the $C$. elegans biomass was seen, in the past, as a negative aspect for a biosorbent material, because it did not allow the recovering and the reuse of precious heavy metals [12]. However, in our opinion, this characteristic could be a strength in textile wastewater treatment, as this study has shown. Actually, this versatility makes biosorption effective also towards pollutants whose concentration and activity remains unchanged trough other treatments, as shown by the salts measurements performed before the biosorption experiments.

The results of the chemical analysis pointed out some criticisms: the standard methods commonly used are often based on colorimetric reactions and, thus, the colour of this kind of wastewaters can interfere with the analysis reading of COD and surfactants. In particular, in some cases, surfactants were impossible to determine, or showed even an increase after the biosorption treatment. However, since $C$. elegans biomass was never put in contact with this kind of molecules during the biomass preparation, a release of surfactants during the biosorption treatment seems to be unrealistic.

Also salts determination by means of chromatographic analysis raised some problems. Actually, in some cases an increase of salt was recorded after biosorption treatment, but, as for surfactants, a release by the fungal biomass can be excluded. Probably, chromatographic analyses were affected by the turbidity and the high amount of suspended solids characterizing textile wastewaters. To overcome these drawbacks, some authors suggest the use of potentiometric method, not affected by colour and turbidity [8].

Wastewaters coming from a selected treatment plant were undergone to biosorption experiments with different biomass amounts in order to optimize the process. The decolourisation rate was proportional to the biomass amount in the case of effluents after activated sludge (A2), whereas for the effluent after decolourisation with polyelectrolyte (A3) it was not found a clear correlation among decolourisation and biomass amount. Probably, this could be due to the higher dye concentration in A2, which requires higher biomass amount. The results of $\mathrm{Cl}^{-}$and $\mathrm{SO}_{4}{ }^{2-}$ removal pointed out that the optimum biomass-wastewater ratio is $5 \mathrm{~g} \mathrm{~L}^{-1}$ for the treatment of both $\mathrm{A} 2$ and $\mathrm{A} 3$. For the effluent after ozonation treatment (A4) the optimal amount reduced to $0.5 \mathrm{~g} \mathrm{~L}^{-1}$.

About the ecotoxicological aspect of wastewaters, the tested organisms responded differently to wastewaters exposure, and $C$. sativus resulted the most sensitive one. It is interesting to note that this angiosperm rarely considered in ecotoxicity study and, at the best of the authors' knowledge, never for the evaluation of textile wastewaters toxicity $[18,19]$. On the contrary, D. magna resulted totally insensitive to the tested wastewaters, although this organism is indicated by the literature as one of the most suitable target for testing textile wastewaters toxicity [20]. However, since different organisms respond differently to toxicants, the use of a single test for the toxicity assessment results an incorrect procedure. Despite this, batteries are rarely carried out at the discharging phase of a wastewater, due to the absence of a specific legislation about their compulsoriness. Moreover, the fact that several 
analyses are time consuming and require specific expertise dissuades industries from performing more than one test.

The wastewater toxicity remained substantially unchanged after decolourisation with polyelectrolyte and oxidation process. Actually, as already demonstrated by several papers dealing on physical-chemical treatments (i.e., ultrasound and photochemical treatment) and biological degradation mainly of azo dyes turn often in colourless but toxic substances [21,22]. Biosorption treatment, instead, quite totally decreased samples toxicity, indicating that the toxic substances were removed.

\section{Conclusions}

C. elegans biomass resulted effective in removing dyes from different real wastewaters, irrespective of their composition; the decolourisation process was often coupled to the removal of salts and surfactants and corresponded to an actual detoxification of wastewaters.

The biosorption seems thus a suitable process for treating the samples with higher concentration of pollutants and the biomass amount can be optimized according to the wastewater characteristics.

Biosorption with $C$. elegans biomass is a quick process that can be combined with other physical-chemical and biological techniques to reach the complete removal of pollutants and the reuse of water. The versatility of $C$. elegans in adsorbing dyes, salts, heavy metals and surfactants makes it a promising novel biosorbent for different biotechnological applications.

\section{Acknowledgements}

This work was supported by University of Turin and MARCOPOLO ENGINEERING S.p.a. (Borgo S. Dalmazzo, Italy). Authors wish to express their thanks to the Region of Lombardy for the partial financial support of this work through the projects Biotex-2007-4052 and Puracqua.

\section{References}

1. Hai, F.I.; Yamamoto, K.; Fukushi, K. Hybrid Treatment System for Dye Wastewater. Crit. Rev. Env. Sci. Tec. 2007, 37, 315-377.

2. Robinson, T.; McMullan, G.; Marchant, R.; Nigam, P. Remediation of dyes in textile effluent: A critical review on current treatment technologies with a proposed alternative. Bioresource Technol. 2001, 77, 247-255.

3. Baughman, G.L.; Perenich, T.A. Fate of dyes in aquatic systems: 1 Solubility and partitioning of some hydrophobic dyes and related compounds. Environ. Toxicol. Chem. 1988, 7, 183-199.

4. Aksu Z. Application of biosorption for the removal of organic pollutants: A review. Process Biochem. 2005, 40, 997-1026.

5. Vijayaraghavan, K.; Lee, M.W.; Yun, Y.S. A new approach to study the decolorization of complex reactive dye bath effluent by biosorption technique. Bioresource Technol. 2008, 99, 5778-5785. 
6. Oliveira, D.P.; Carneiro, P.A.; Sakagami, M.K.; Zanoni, M.V.B.; de Aragão Umbuzeiro, G. Chemical characterization of a dye processing plant effluent-Identification of the mutagenic components. Mutat. Res. 2007, 626, 135-142.

7. Yuan, S.Y.; Yu, C.H.; Chang, B.V. Biodegradation of nonylphenol in river sediment. Environ. Pollut. 2004, 127, 425-443.

8. Bisschops, I.; Spaniers, H. Literature review on textile wastewater characterization. Environ. Technol. 2003, 24, 1399-1411.

9. Vishnu, G.; Palanisamy, S.; Kurian, J. Assesment of fieldscale zero liquid discharge treatment systems for recovery of water salt from textile effluents. J. Clear Prod. 2008, 16, 1081-1089.

10. Hessel, C.; Allegre, C.; Maisseu, M.; Charbit, F.; Moulin, P. Guidelines and legislation for dye house effluents. J. Environ. Manage. 2007, 83, 171-180.

11. Causapé, J.; Quílez, D.; Aragüés, R. Salt and nitrate concentrations in the surface waters of the CR-V irrigation district (Bardenas I, Spain): Diagnosis and prescriptions for reducing off-site contamination. J. Hydrol. 2004, 295, 87-100.

12. Gadd, M.G. Biosorption: Critical review of scientific rationale, environmental importance and significance for pollution treatment. J. Chem. Technol. Biotecnol. 2009, 84, 13-28.

13. Kaushik, P.; Malik, A. Fungal dye decolourization: Recent advances and future potential. Environ. Int. 2009 35, 127-141.

14. Prigione, V.; Tigini, V.; Pezzella, C.; Anastasi, A.; Sannia, G.; Varese, G.C. Decolourisation and detoxification of textile effluents by fungal biosorption. Water Res. 2008, 42, 2911-2920.

15. Costan, G.; Bermingham, N.; Blaise, C.; Ferard, J.F. Potential ecotoxic effects probe (PEEP): A novel index to assess and compare the toxic potential of industrial effluents. Environ. Toxicol. Water Qual. 1993, 8, 115-140.

16. Savin, I.I.; Butnaru, R. Wastewater characteristics in textile finishing mills. Environ. Eng. Manage. J. 2008, 7, 859-864.

17. Prigione, V.; Zerlottin, M.; Refosco, D.; Tigini, V.; Anastasi, A.; Varese, G.C. Chromium removal from a real tanning effluent by autochthonous and allochthonous fungi. Bioresource Technol. 2009, 100, 2770-2776.

18. Reis, J.L.R.; Dezotti, M.; Sant'Anna G.L. Toxicity evaluation of the process effluent streams of a petrochemical industry. Environ. Technol. 2007, 28, 147-155.

19. Andreozzi, R.; Canterino, M.; Di Somma, I.; Lo Giudice, R.; Marotta, R.; Pinto, G.; Pollio, A. Effect of combined physico-chemical processes an the phytotoxicity of olive mill wastewaters. Water Res. 2008, 42, 1684-1692.

20. Verma, Y. Acute toxicity assessment of textile dyes and textile and dyes industrial effluents using Daphnia magna bioassay. Toxicol. Ind. Health 2008, 24, 491-500.

21. Vandevivere, P.C.; Bianchi, R.; Verstraere, W. Treatment and reuse of wastewater from the textile wet-processing industry: review of emerging technologies. J. Chem. Technol. Biotechnol. 1998, 72, 289-302. 
22 Husain, Q. Potential applications of the oxireductive enzymes in the decolorization and detoxification of textile and other synthetic dyes from polluted water: A review. Crit. Rev. Biotechnol. 2006, 26, 201-221.

(C) 2010 by the authors; licensee MDPI, Basel, Switzerland. This article is an open access article distributed under the terms and conditions of the Creative Commons Attribution license (http://creativecommons.org/licenses/by/3.0/). 